\title{
Distribution of practice in the classical conditioning of planarians $1,2,3$
}

F. T. CRAWFORD, PATSY A. LIVINGSTON AND F. J. KING

FLORIDA STATE UNIVERSITY

Eighty Ss were divided into four groups receiving training conditions of either light, shock, light paired with shock, or neither light nor shock. Half of each group were given trials $30 \mathrm{sec}$. apart and the remainder were given trials $60 \mathrm{sec}$. apart. Conditioning occurred only among $S$ s given paired light and shock with spaced training producing significantly greater conditioning. Half of all Ss were then given either massed or spaced extinction trials. Massing and spacing of acquisition trials were found to be of more significant influence upon rate of extinction than were the massing and spacing of extinction trials.

The present problem was designed to study the effect of massed and spaced trials upon the classical conditioning of planaria.1s. Cornwell (1960) appears to have been the first to be interested in such a problem. His results indicated that distribution of practice was not an important variable and that the occurrence of a conditional response may have been due to sensitization since response frequency was independent of the temporal contiguity of the light and shock during conditioning. Cornwell used a distribution of trials that were essentially all massed. The present study, therefore, employed control groups for sensitization and a clearer separation between massed and spaced trials. Method

Eighty Ss (Dugesia doratocephala) were divided into four groups receiving training conditions of either light (L), shock (S), an experimental group in which light was paired with shock (E), or neither light nor shock (NLNS). The apparatus used was similar to that described by McConnell, Cornwell, \& Clay (1960). Half of the Ss in each group were given massed (M) trials having an intertrial interval of approximately $30 \mathrm{sec}$, and the remainder had spaced trials (S) with an interval of approximately $60 \mathrm{sec}$. Since no $\mathrm{S}$ was given a trial unless gliding or moving in a straight path the intertrial intervals were actually between $20-40 \mathrm{sec}$. and 50-70 sec. Ss were given 150 consecutive acquisition trials. On any given trial the duration of light presentation was 3 sec., and the duration of shock presentation was $1 \mathrm{sec}$. In the group receiving paired light-shock (E), the stimuli overlapped during the final second. Following acquisition training each of the groups were given an immediate 25 extinction trials to light presentation alone. Each of the groups were further subdivided so that half received massed (M) and half received spaced (S) extinction trials. The occurrence of turning response and of body contractions was noted during the presentation of each trial.

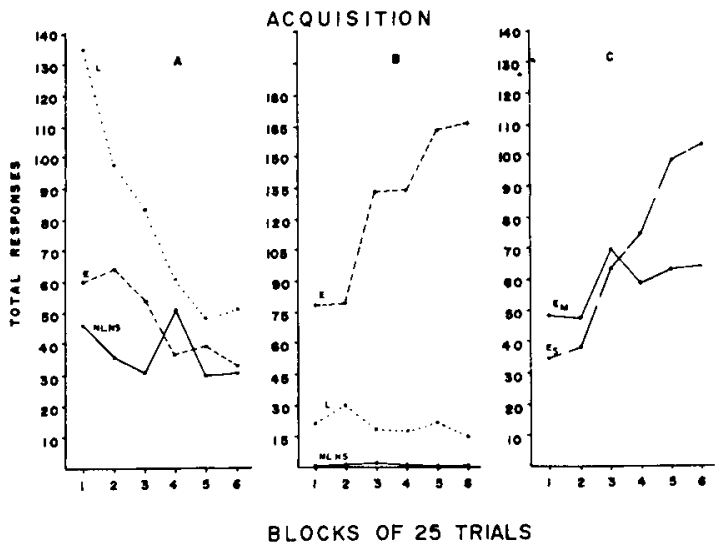

Fig. 1. Acquisition data for (A) turning responses (B) body contractions, and $(C)$ body contractions among experimental subgroups.

\section{Results and Discussion}

From the acquisition curves it may be seen that there was a progressive decline in turning responses (Fig. 1A) although the number of turning responses in the light control (L) group was initially very high. This is interpreted as an indication that the level of illumination employed was not a wholly neutral stimulus even though there appeared to be adaptation to the light stimulus by the end of the acquisition trials. Differences between these three groups (L, E, NLNS) were nonsignificant. Examination of the data on body contractions during acquisition (Fig. 1B) shows a low rate of response in both the L group and the NLNS group with a pronounced increase in response rate in the $\mathrm{E}$ group. These differences are significant at beyond the $1 \%$ level. During acquisition no record was kept of turning responses for the $\mathrm{S}$ group, but body contractions occurred on every trial.

The acquisition curves for the $\mathrm{E}$ subgroups receiving massed and spaced trials are shown in Fig. 1C. The group receiving spaced trials had a terminal $41 \%$ body contractions as contrasted to $26 \%$ in the group receiving massed trials. An analysis of variance shows these groups to be significantly different at beyond the $5 \%$ level.

The extinction data are shown in Fig. 2. It can be observed that the frequency of turning responses (Fig. 2A) continues to drop in all groups. The differences between groups were not significant. During extinction the frequency of body contractions in the $\mathrm{E}$ group (Fig. 2B) were, however, significantly different from the other three groups. The breakdown of massed- 


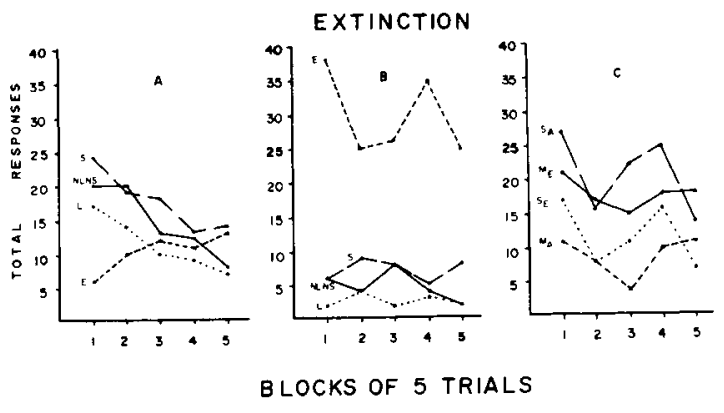

Fig. 2. Extinction data for (A) turning responses (B) body contractions, and (C) body contractions among experimental subgroups.

spaced conditions of acquisition as compared to the massed-spaced conditions of extinction is shown in Fig. 2C. The conditions of acquisition produced greater effects than the conditions of extinction in that all $\mathrm{E}$ subgroups receiving spaced acquisition trials are significantly different from all subgroups receiving massed acquisition trials whereas none of the subgroups receiving differential distribution of trials during extinction were significantly different from one another.

A sample of the data taken from the $\mathrm{E}$ group, for both acquisition and extinction, was independently judged. The resultant reliability coefficient was .96 .

In summary, conditioning occurred only among Ss receiving paired light and shock and only for the meas- ure of body contractions. The spaced training procedure produced a significantly larger number of conditioned responses than did the massed training procedure. Massing and spacing of acquisition trials were found to have a more significant effect upon rate of extinction than massing and spacing of extinction trials. It is to be noted that Ss of the present experiment demonstrated considerable resistance to extinction compared to that reported by Baxter \& Kimmel (1963). It appears that the generalization concerning the relative efficacy of distributed practice as compared to massed practice applies to the lowly worm as well as to the higher vertebrates.

\section{References}

Baxter, R., \& Kimmel, H. D. Conditioning and extinction in the planarian. Amer. J. Psychol., 1963, 76, 665-669.

Cornwell, P. A preliminary study of pseudo-conditioning under conditions of massed stimulation in the planarian. Worm Runner's Digest, 1960, 2, 101-108.

McConnell, J. V., Cornwell, P. R., \& Clay, Margaret. An apparatus for conditioning planaria. Amer. J. Psychol., 1960, 73, 618-622.

\section{Notes}

1. This research was supported in part by a grant from the Florida State University Research Council.

2. The statistical analyses were made possible in part by NSF Grant (No. GP671) to the Florida State University Computation Center.

3. This research is taken from a Master's thesis earned by the second author. A portion of the research was presented at the 1964 American Psychological Association meeting by the senior author. 